Article

\title{
Self-Efficacy in Multimodal Narrative Educational Activities: Explorative Study in a Multicultural and Multilingual Italian Primary School
}

\author{
Monica Banzato * and Francesca Coin \\ banzato@unive.it (M.B.),francesca.coin85@unive.it (F.C.) \\ * Corresponding author \\ Submitted: 15 December 2018 | Accepted: 28 February 2019 | Published: 11 June 2019
}

Department of Linguistics and Comparative Cultural Studies, Ca' Foscari University of Venice, 30123 Venice, Italy; E-Mails:

\begin{abstract}
The international migration changed the situation in the Italian school system: it is asked to update educational practices with new pedagogical models of narration and expression (multiliteracies and multimodality) and to promote digital skills from childhood. Self-efficacy, more than the actual performance, influences the will to try again and not give up. Few studies are available on how narrative self-efficacy affects expressive development, especially in school contexts characterized by multilingualism and multiculturalism. This exploratory survey aims to investigate the narrative self-efficacy of eighteen 8-year-old children attending primary school, with a significant presence of international migrant children (two out of three). For three months, these students were involved in multimodal narrative learning activities through gestural/mime languages (theatre), visual languages (drawings), verbal languages (oral and written) and digital languages (digital video narration). The research questions were: (1) Does the multimodal workshop influence the self-efficacy beliefs of the narrative skills perceived by Italian students (L1) and international migrant students (L2)? (2) Does the most influence come from the mime/gestural, the digital video or the entire multimodal narrative activities? (3) In which aspects of the narrative is the self-efficacy most influenced by the multimodal workshop for L1 and L2 groups?
\end{abstract}

\section{Keywords}

international migrant students; multicultural; multilingualism; multiliteracies; multimodality; narrative skills; primary school; self-efficacy

Issue

This article is part of the issue "Critical Perspectives on Digital Literacies: Creating a Path Forward", edited by Hiller A. Spires (North Carolina State University, USA).

(C) 2019 by the authors; licensee Cogitatio (Lisbon, Portugal). This article is licensed under a Creative Commons Attribution 4.0 International License (CC BY).

\section{Introduction}

For some years, students with migratory origins have represented the dynamic component of the Italian school system. They contribute by their numerical growth to containing the decline in the overall school population, which results from the continuing decline of Italian students. In the five years from 2011/2012 to 2015/2016, Italian students decreased by 193,000 , from $8,205,000$ to $8,012,000(-2.3 \%)$, while foreign students increased by $59,000(+7.8 \%)$, going from 756,000 to 815,000 (Ministero dell'Istruzione dell'Università e della Ricerca [MIUR], 2017).
The data on literacy (Santagati \& Ongini, 2016) reveals that foreign students get systematically lower results than their Italian peers, even if the gaps between Italian and second-generation foreign students are smaller than those recorded for first generation students. The difference is more pronounced for the expressive disciplines such as Italian (about 10 percentage points) than the logical-mathematical disciplines (about 6 points). This gap tends to increase by another 4 points in Italian and 1 point in mathematics in secondary schools (OECD-PISA, 2012).

Many public and private projects are being implemented for the acquisition of the Italian language by 
newly arrived students, but they are sufficient to teach them only basic skills. Expressive literacy, therefore, is considered one of the emergency areas in which investment from primary school on is required, both for the purposes of social, cultural and digital inclusion of foreign students and to contain the growing dropout rate that afflicts secondary schools. The higher schools, indeed, show a school dropout rate-especially for foreign students ( $34.4 \%$ against $14.8 \%$ of Italian students)higher than comparable European schools $(22.7 \%$ and $11 \%$ respectively; OECD-PISA, 2012).

At the same time, teachers are challenged (1) by international educational and pedagogical research and (2) by European Union (Redecker, 2017) and national education policies (MIUR, 2016) to update their teaching methods. They are required to move from monoliteracy to multiliteracy educational practices, starting with primary school classes. The pedagogical approach of multiliteracies, a term coined by the New London Group (NLG, 1996), begins with a critique of traditional education based on a single literacy (i.e., centred on a single language, a single national form of language and culture). This approach requires rethinking education goals and teaching methods, with the aim of incorporating a wide range of literacies (plural) in order to bring together forms of creation and meaning based on a plurality of languages and modalities. This requirement is based on two premises: (1) the growing importance of cultural and linguistic diversity due to the effects of international migration at the global level and (2) the increasing variety of languages and ways of thinking, creating and communicating meaning available in digital environments. As Wilber (2010) states new literacies are multimodal (Jewitt, 2009; Kress, 2000; Walsh, 2010), or composed of multiple modalities-"configurations of images, gesture, gaze, body posture, sound, writing, music, speech, and so on" (Jewitt, 2008, p. 243). The digital text is different from the printed page. This means that thinking, reading and writing have also changed because readers (in receiving) and writers (in producing) must make sense of the multiple modes of communication (video, images, etc.). It is proposed that the use of multimodal languages could help to reduce the communication disadvantages that hold back foreign students. This proposition challenges the common, and still widespread, understanding of school literacy: the focus shifts from written text to multimodal structures which are created, understood, shaped and reshaped (in the case of remixing).

Multimodal learning had already been studied in the pre-digital era (Stoll-Lillard, 2005), as for example in the works developed by Montessori according to which "motor behaviour and cognition are closely intertwined and physical movement can improve thought and learning" (Massaro, 2012, p. 2378). Today, when multimodal digital environments envelop/surround the development of children from birth, they are embedded in an "embodied learning, involving multiple sensory systems and systems of action of the learner" (Massaro, 2012, p. 2378). The true challenge for teachers is to develop expressive literacies, while keeping the children's self-efficacy high for as long as needed to learn multicultural and multimodal languages. In this complex context, there is an important gap in the research on the self-efficacy of skills developed through multimodal narrative academic activities promoted at primary school. In fact, (1) narrative plays a central role in literacy in primary school for the development of the child's verbal skills (oral and written). However, the potential of multimodal narrative practices still seems to be little explored and diffused in Italian schools, which generally favour activities centred on written verbal modes, and where international students leave with inevitable disadvantages (see data above); (2) little is known about how multimodal teaching practices influence self-efficacy (see Section 2) in multicultural and multilingual classes. Self-efficacy is considered a crucial factor for school adaptation and success. The term refers to "people's judgments of their capabilities to organize and execute courses of action required to attain designated types of performances" (Bandura, 1986, p. 391). Self-efficacy beliefs are found to be related to students' academic motivation, self-conception, goal orientation, performance levels and anxiety, as well as success and risk of drop out (Caprara et al., 2008; Usher \& Pajares, 2008; Zimmerman, 2002). More than the performance itself, the perception of one's self-efficacy determines the tenacity with which individuals make greater or lesser effort to improve their learning.

Narration is a fertile ground on which to train the aforementioned skills. For this reason, the exploratory survey presented in this article aims to investigate the self-efficacy of narrative skills of students in a thirdgrade class of 18 children (age 8 ) of a primary school with a strong presence $(60 \%)$ of international migrants (group L2) and 40\% Italian students (group L1) involved in activities of multimodal narrative learning through mime/gestural languages (realized through shadow theatre), visual languages (drawings that narrate theatrical scenes realized by the children) and verbal languages (spoken/written to narrate the drawn scenes), assembled at the end into a digital video narration (see Figure 1 in the Appendix).

\section{Related Work: Self-Efficacy, Multimodality, and Multicultural and Multilingual School Contexts in Primary School}

Very little research has tried to understand the relationships between these four themes: (1) self-efficacy, (2) activities of multimodal narrative learning, and (3) multicultural and multilingual school contexts in the (4) primary school.

In the literature, much of the research focuses mainly on academic self-efficacy (reading, writing and mathematics; Bandura, 1997); such research is usually limited to English-speaking North American monolinguals (Gwénaëlle \& Usher, 2011). Research in Europe, and par- 
ticularly in Italy, is mostly limited to monolingual schools (Caprara et al., 2008) and is even more limited in multilingual schools. Most of the research regarding selfefficacy in academic literacy is directed at middle schools onwards, while the number of inquiries investigating the sources of self-efficacy, particularly among primary school students, decreases significantly; although this is the period in which children are particularly receptive and begin to develop the first phases of this important construct (Usher \& Pajares, 2008). Moreover, the research of the last forty years has mainly investigated school self-efficacy developed through educational transmission (i.e., teacher centred; OECD, 2009) approaches (for reasons of historical contingency; Caprara et al., 2008; OECD, 2009). The research gap increases if we take into account the variable multilingual and multicultural school contexts. There are research studies but they are concentrated mainly in North America, and they investigate high school age students and English speaking cohorts. From this research, we learn that there is a correlation between low self-efficacy beliefs and the high risk of early school leaving among foreign students (e.g. Afro-American, Hispanic and Caucasian; Pajares, 2003). The performance of foreign students decreases as they continue their studies. Moreover, once negative perceptions are rooted in student beliefs, they become resistant to change even in the face of obvious improvements (Bandura, 1986; Nisbett \& Ross, 1980). However, Klassen and Georgiou (2008; Klassen, 2002; Klassen, 2004) observe that perceptions of self-efficacy are still investigated in too isolated a way in homogeneous and heterogeneous racial studies.

Restricting our research on self-efficacy to multimodal narrative practices in multicultural and multilingual primary schools by means of databases such as ERIC, PsycINFO, SCIENCEDIRECT, SAGE and SCOPUS has not yielded satisfactory results.

There is research on multimodal narrative activities, but it is mainly developed with qualitative methods (in particular the semiotic approach) for adolescent students (Binder \& Kotsopoulos, 2011; Jewitt, 2008), sometimes in the presence of foreigners (Honeyford, 2014; Ntelioglou, Fannin, Montanera, \& Cummins, 2014), but it does not specifically take into account psychometric constructs such as self-efficacy. There is research that takes into account self-efficacy in the context of the educational method of digital storytelling, but this focuses in particular on the digital skills of the students (Ballast, Stephens, \& Radcliffe, 2008; Banaszewski, 2005; Heo, 2009; Yoon, 2013) or on the effectiveness of a particular digital environment used to build digital storytelling (Dogan, 2015; Ibanez, Aylett, \& Ruiz-Rodarte, 2003; Scaffidi \& Chambers, 2012; Shin, \& Park, 2008). We did not consider this research because our exploratory study is not focused on the use of "digital" + "storytelling", but on the multimodal narrative learning processes in reception and production that start from narrative activities/gestural expressions (analogical modality) to visual and verbal activities (both analogical and digital modalities) and to digital videos (digital modality).

We have verified the existence of a research gap on self-efficacy beliefs developed through multimodal narrative activities, promoted since childhood in class contexts characterized by multilingualism and multiculturalism. Given the nature of the experimental activities proposed in our work and the diversity of the contexts of origin, we decided not to compare the results of our students with those obtained from the literature mentioned above.

\section{Aim of the Study}

The exploratory survey presented in this article aims to investigate self-efficacy regarding the narrative skills of 18 eight-year-old children. They attend the third grade class in a primary school with a strong presence $(60 \%)$ of international migrant students (11 pupils) and $40 \%$ Italian students (7 pupils). We investigated the children's self-efficacy regarding narration, as that is a central activity in the development of a literacy curriculum in primary schools. This type of study provides an opportunity to document the delicate transition phases from the traditional school comprised of pupils with a similar background to the current ones (with a strong presence of international migrants, bearers of different literacies and languages). It also encourages reflection on the strengths and weaknesses of these learning modalities in relation to the selfconfidence perceived by children who speak Italian as their mother tongue (L1) and as their second language (L2). The goal is to provide results that serve as a starting point for further investigation of multimodality teaching. Multimodal narrative activities are presented here as a relevant educational/pedagogical inquiry on the passage from monoliteracy to multiliteracies. The children were involved in multimodal narrative learning activities through mime/gestural languages (in this case, shadow theater), visual languages (drawings for theatrical scenes) and verbal languages (spoken/written sentences to narrate the plot). These varied activities were assembled at the end into a digital video narration. The experimentation, which was developed over three months through a total of 40 hours of training, was initially based on an adaptation for children of Shakespeare's play The Merchant of Venice (Tosi, 2015). The phases of the workshop alternated between passive and active narrative forms: (1) listening to an oral version of The Merchant of Venice; (2) reading aloud the story accompanied by illustrations; (3) interpreting the scenes through mime and gestural language realized in a shadow theater; (4) identification of the scenes by the children viewing them as spectators; (5) narration by the children of the main scenes of The Merchant of Venice through drawings and short descriptions, first oral and then written; (6) digitization of drawings and short written narratives; (7) assembly of the materials produced by 
the children to create a short narrative video; (8) finally, sharing of the end products with the children's parents.

Four research questions guided the study (see Figure 1 in the Appendix):

RQ1: Does the multimodal laboratory influence the self-efficacy beliefs about their narrative skills perceived by Italian students (L1) and international migrant students (L2)?

RQ2: Does the mime/gestural narrative influence the self-efficacy beliefs about their narrative skills perceived by Italian students (L1) and international migrant students (L2)?

RQ3: Does the digital video narrative influence the self-efficacy beliefs about their narrative skills perceived by Italian students (L1) and international migrant students (L2)?

RQ4: In which aspects of the narrative is self-efficacy most influenced by the multimodal workshop for Italian (L1) and international migrant (L2) students?

\subsection{Participants}

Eighteen eight-year-old students participated in the educational project. The class group consisted of 7 Italian students, 6 females and 1 male (L1 group) and 11 international migrant students, 8 females and 3 males (L2 group). The L2 group comes from seven different countries: Albania, Bangladesh, China, Egypt, Macedonia, Moldova, Philippines. Among the eleven foreign pupils in our class, six were born in Italy. The other five arrived in Italy before the age of three, so the majority of them attended three years of preschool. They speak Italian at school and the family language at home. All foreign pupils can speak Italian at a level sufficient for daily communication. Three of them show poor lexicon and syntax. Seven of them can read with the same fluency as their Italian classmates, whereas four read slower and make more mistakes. Only four children have a written production comparable with Italian peers. Seven use shorter sentences, poorer lexicon and make a greater number of orthographical mistakes. From the point of view of socialization, the class group appears cohesive and there are no signs of exclusion due to cultural differences. However, foreign children are less involved in play-activities outside the school, due to the difficulties of communication between parents. All of the children use tablets or PCs to watch cartoons, movies and play games. Consequently, their computer activities are passive rather than productive.

\subsection{Procedure}

Before the project started, approval and authorizations from the school and parents were obtained. Three questionnaires were designed: a narrative pre-test, focusing on general narrative self-efficacy beliefs and two posttests aimed at detecting self-assessments about gestural and mime narrative skills (post-test 1 theater), and narrative abilities based on digital video narration (posttest 2 video). The narrative pre-test was administered before the activities began, the post-test 1 theater after the shadow theater activities and the post-test 2 video after the digital video narration. A trial version of the questionnaire was verified through a group of volunteers, three Italian and three foreign third-grade students. They were asked to think aloud while answering the items. In addition, they were asked to write down words or phrases they did not fully understand. Based on their feedback, some items were modified to make the questionnaire more easily readable. The administration of the tests took place collectively. The researcher read aloud the questions to make sure everyone understood the text. A collective and indirect way of collecting information was preferred, thinking that this would put the children equally at ease (both the L1 group and the L2 group), giving them time to understand the question and think about the answer. The teachers were present at the administration and gave positive feedback on the accuracy with which the children responded. Subsequently, the statistical elaboration confirmed that the children's responses were significant and not due to chance (see Sections 3.3. and 4).

\subsection{Instrument}

The questionnaire items were written as first-person statements. Students were asked to evaluate their agreement level on a Likert scale from 1 (not true) to 4 (completely true). Although most of the items were positively formulated, some were formulated negatively (Bandura, 1997). The perceived effectiveness is measurable only through self-assessment, as only the subject can provide valuations of their convictions. The items investigate only the perception of being able to do, and not wanting to do (intention) or being used to do (habit). Many tools have been developed in the literature to measure perceived self-efficacy for different groups of the population, ranging from scholastic to working contexts. However, we did not find a validated questionnaire about multimodal activity and narrative literacy skills (see Sections 1 and 2). Inspired by Chen, Gully and Eden (2001) General Self-Efficacy Scale (GSES), we decided to design an ad hoc questionnaire for the purpose of investigating some of the crosscutting categories of our multimodal narrative activities.

Four categories were identified: Thinking Actions, Realizing Actions, Thinking Emotions and Realizing Emotions. Later, we added Feedback from others and SelfAssessment. Each item was designed to promote thinking about the skills required in classic narration; next, a corresponding form was created for the theatrical and the video narration activities. Below is a brief description of the categories, with sample items:

1. Thinking Actions is related to the children's beliefs about their capacity to imagine characters' actions 
in a narrative. An example of a classic narration item: am I able to imagine the actions of the characters in a story? An example of an item of theatrical narration: Was I able to imagine the actions of the character I played in my scene? An example of an item of the video narration: Was I able to think of the sentences to describe the actions that took place in the video scene?

2. Realizing Actions is related to the children's convictions of their ability to describe the actions of a narration. An example of an item concerning classic narration: am I able to recount the actions of the characters? For verification, we asked about their beliefs regarding their ability to describe actions in their daily lives. An example of an item: am I able to recount my adventures? An example of an item from the theatrical narration: was I able to mime the action of my character? An example of an item from the video narration: was I able to imagine an effective action sequence to tell the story of my video? Since children were not Italian native speakers, we wanted to investigate in more depth the cause of any difficulties they encountered. To accomplish that, we isolated a sub-category of more specific questions concerning their ability to find the right words to describe actions (Right word and gesture). An example of an item regarding classic narration: am I able to find the right words to narrate the actions of the characters?

3. Thinking Emotions is related to the children's beliefs about their ability to imagine and understand the emotions of the characters in a story. An example of an item from classic narration: am I able to understand how the characters in a story feel? An example of a theatrical narrative item: was I able to understand how the character in my scene was feeling?

4. Realizing Emotions is based on the children's beliefs about their ability to describe the characters' emotions in a story. An example from a classic narrative: am I able to describe a character's emotions? An example from a theatrical narration: was I able to mime the emotions of my character? And from the deeper version: was I able to find the right gestures to mime the emotions of my character?

5. Feedback from others is related to the children's beliefs about their ability to tell a story and be understood by others. An example of an item from classic narration: when I tell a story to others, do they understand me? An example of an item from the theatrical narration: did my classmates immediately guess the scene I was representing?

6. Self-Assessment is related to the children's beliefs about their ability to tell a story in Italian and in their language of origin. An example item: am I able to narrate a story in Italian?
The array of the questionnaire consists of 23 items in total ( 9 in the pre-test, and 7 for the post-test 1 theater and 7 for the post-test 2 video). When putting it into written form, we paid particular attention to: a) the formulation, taking into account that the majority of children are international migrants who speak Italian as L2; b) the content, which had to be consistent with the activities of the educational workshops and the objectives of the exploratory study; $c$ ) the time needed to administer the questionnaire, especially the post-tests, which took place after long sessions of educational activities.

Before proceeding with the analysis of the results, the reliability of the questionnaire was estimated through Cronbach's Alfa score. From the calculation of this index, we obtained a good result ( $\alpha 0.846)$, also confirmed by the statistics on the items. The result is again confirmed by the fact that, trying to remove one item at a time from the questionnaire, the value of $\alpha$ remains lower than 0.846 . The total correlation of the items is always higher than 0.4 for each item, demonstrating a good internal consistency of the questions.

Since the number of questions and participants is very small, it is preferable to illustrate the data not as single categories (from 1 to 4), but rather by grouping them into meta categories. The reliability of the grouped questions was then evaluated according to the groupings: Thinking Narration (cat. 1+3), good, $\alpha$ 0.809; Realizing Narration (cat. 2+4), discrete, $\alpha$ 0.703; Expressing Actions (cat. 1+2), discrete, $\alpha$ 0.732; Expressing Emotions (cat. $3+4)$, sufficient, $\alpha 0.636$. The items Feedback from others (cat. 5) and Self-Assessment (cat. 6) did not obtain sufficient alpha $(\alpha=0.581)$. Therefore we decided not to include them in subsequent analyzes.

\section{Results Analysis}

Before calculation of the Student t-test, a normality test was carried out on the data, to verify that they were distributed in a Gaussian manner. In particular, because our sample was composed of fewer than 50 subjects, we chose the Shapiro-Wilk test, obtaining a value of sig. equal to 0.293 for pre-test narration compared to the post-test 1 theater; 0.388 between pre-test narration and post-test 2 video; 0.060 between post-test 1 theater and post-test 2 video, confirming the normal distribution of data.

A t-test for paired samples was conducted to assess if there was a statistically significant difference between the mean scores in beliefs about their narrative skills perceived by the students before and after each of the main steps. The results of the t-test are especially significant in the final steps, i.e. in the transition between the posttest 1 theater and the post-test 2 video $(t)(17)=-3.50$, $p<.005)$ and between pre-test narration and post-test 2 video $(\mathrm{t}(17)=-2.79, \mathrm{p}<.01)$.

Grouping Thinking Narration 1+3: Grouping selfefficacy data to investigate children's ability in Thinking Narration records a statistically significant change from 
post-test 1 theater to post-test 2 video (t $(17)=-2.41$, $p<.02$ ). While, the change in pre-test narrative and posttest 2 video is not statistically significant, it shows a slight increase (see table 1.).

Grouping Realizing Narration 2+4: Grouping data for Realizing Narration, we can see how the change in selfefficacy is statistically significant between the pre-test narration and post-test 2 video ( $\mathrm{t}(17)=-2.89, \mathrm{p}<.01$ ) and between the post-test 1 theater and the post-test 2 video (t $(17)=-3.57, \mathrm{p}<.002$ ) (see table 1.).

Grouping Expressing Actions 1+2: Grouping data by Expressing Actions, it is possible to see that the change in self-efficacy is statistically significant between the pretest narration and post-test 2 ( $t(17)=-42.46, p<.02$ ) and between the post-test 1 theater and the post-test 2 video ( $\mathrm{t}(17)=-3.55, \mathrm{p}<.002$ ) (see table 1.).

Grouping Expressing Emotions 3+4: Grouping data for Express Emotions, we can see the change in selfefficacy is statistically significant between the pre-test and post-test 2 video ( $\mathrm{t}(17)=-3.36, \mathrm{p}<.004)$ and between the post-test 1 theater and the post-test 2 video (t (17) $=-2.95, \mathrm{p}<.009$ ) (see table 1.).

Grouping Right Words and Gestures: It is important to remember that for the theater questions the children's self-efficacy beliefs were measured on gestural narrative communication skills, while the pre-test narrative and post-test 2 videos measured the ability to express themselves with the right words and sentences. The difference between the post-test 1 theater and posttest 2 video $(t(17)=-2.69, p<.01)$ is statistically significant (see table 1.).

Further subdividing the data by groups of students, L1 (see table 2.) and L2 (see table 3.), we can see an increase in the average scores for both groups in all the categories of questions. Because of the small number of participants and the further subdivision into subgroups, the statistical significance is only present in a few comparisons; however, the tendency to improvement is evident.

Table 1. Pre-test, post-test 1 theater and post-test 2 video: means, standard deviations and results of t-test for self-efficacy divided by categories for all children.

\begin{tabular}{|c|c|c|c|c|c|c|c|c|c|c|c|c|}
\hline $\mathrm{L} 1 *+\mathrm{L} 2 * *$ & $\begin{array}{r}\text { Mean } \\
\text { Pre } \\
\text { Narration }\end{array}$ & DS & $\begin{array}{r}\text { Mean } \\
\text { Post1 } \\
\text { Theater }\end{array}$ & DS & $\begin{array}{l}\text { Mean } \\
\text { Post2 } \\
\text { Video }\end{array}$ & DS & $\begin{array}{l}\mathrm{T} \text { (pre- } \\
\text { post1) }\end{array}$ & $\mathbf{p}$ & $\begin{array}{l}\mathrm{T} \text { (pre- } \\
\text { post2) }\end{array}$ & $p$ & $\begin{array}{r}\mathrm{T} \text { (post1- } \\
\text { post2) }\end{array}$ & $p$ \\
\hline $\begin{array}{l}\text { Thinking } \\
\text { Narration } 1+3\end{array}$ & 3.11 & .97 & 3.11 & .67 & 3.58 & .46 & .000 & - & -1.934 & - & -2.411 & $<.02$ \\
\hline $\begin{array}{l}\text { Realizing } \\
\text { Narration } 2+4\end{array}$ & 3.09 & .66 & 3.16 & .66 & 3.61 & .40 & -.619 & - & -2.892 & $<.01$ & -3.575 & $<.002$ \\
\hline $\begin{array}{l}\text { Expressing } \\
\text { Actions } 1+2\end{array}$ & 3.18 & .76 & 3.11 & .75 & 3.63 & .44 & .684 & - & -2.463 & $<.02$ & -3.557 & $<.002$ \\
\hline $\begin{array}{l}\text { Expressing } \\
\text { Emotions } 3+4\end{array}$ & 2.97 & .97 & 3.19 & .62 & 3.63 & .41 & -1.254 & - & -3.367 & $<.004$ & -2.950 & $<.009$ \\
\hline $\begin{array}{l}\text { Right Words } \\
\text { and Gestures }\end{array}$ & 3.09 & .79 & 3.00 & .76 & 3.52 & .52 & .801 & - & -2.006 & - & -2.695 & $<.01$ \\
\hline
\end{tabular}

Notes: ${ }^{*}$ L1 $=$ Italian students; ${ }^{*}$ L2 $=$ international migrant students.

Table 2. Pre-Test, post-test 1 theater and post-test 2 video: means, standard deviations and results of t-test for self-efficacy according to categories for Italian students (L1).

\begin{tabular}{|c|c|c|c|c|c|c|c|c|c|c|c|c|}
\hline L1 & $\begin{array}{r}\text { Mean } \\
\text { Pre } \\
\text { Narration }\end{array}$ & DS & $\begin{array}{r}\text { Mean } \\
\text { Post1 } \\
\text { Theater }\end{array}$ & DS & $\begin{array}{l}\text { Mean } \\
\text { Post2 } \\
\text { Video }\end{array}$ & DS & $\begin{array}{l}\mathrm{T} \text { (pre- } \\
\text { post1) }\end{array}$ & $\mathbf{p}$ & $\begin{array}{l}\text { T (pre- } \\
\text { post2) }\end{array}$ & $p$ & $\begin{array}{r}T \text { (post1- } \\
\text { post2) }\end{array}$ & $\mathbf{p}$ \\
\hline $\begin{array}{l}\text { Thinking } \\
\text { Narration } 1+3\end{array}$ & 3.07 & 1.05 & 3.28 & .48 & 3.57 & .44 & -.660 & - & -1.449 & - & -1.922 & - \\
\hline $\begin{array}{l}\text { Realizing } \\
\text { Narration 2+4 }\end{array}$ & 3.14 & .71 & 3.23 & .63 & 3.53 & .33 & -.372 & - & -1.390 & - & -1.427 & - \\
\hline $\begin{array}{l}\text { Expressing } \\
\text { Actions } 1+2\end{array}$ & 3.28 & .65 & 3.35 & .47 & 3.50 & .40 & -.465 & - & -.776 & - & -1.000 & - \\
\hline $\begin{array}{l}\text { Expressing } \\
\text { Emotions } 3+4\end{array}$ & 2.85 & 1.06 & 3.14 & .62 & 3.64 & .37 & -.834 & - & -2.420 & $<.05$ & -2.646 & $<.03$ \\
\hline $\begin{array}{l}\text { Right Words } \\
\text { and Gestures }\end{array}$ & 3.15 & .71 & 3.14 & .26 & 3.50 & .50 & .053 & - & -1.039 & - & -1.109 & - \\
\hline
\end{tabular}


Table 3. Pre-test, post-test 1 theater and post-test 2 video: means, standard deviations and results of t-test for self-efficacy according to categories for international migrant students (L2).

\begin{tabular}{|c|c|c|c|c|c|c|c|c|c|c|c|c|}
\hline L2 & $\begin{array}{r}\text { Mean } \\
\text { Pre } \\
\text { Narration }\end{array}$ & DS & $\begin{array}{r}\text { Mean } \\
\text { Post1 } \\
\text { Theater }\end{array}$ & DS & $\begin{array}{l}\text { Mean } \\
\text { Post2 } \\
\text { Video }\end{array}$ & DS & $\begin{array}{l}\text { T (pre- } \\
\text { post1) }\end{array}$ & $\mathbf{p}$ & $\begin{array}{l}\text { T (pre- } \\
\text { post2) }\end{array}$ & $p$ & $\begin{array}{r}T \text { (post1- } \\
\text { post2) }\end{array}$ & p \\
\hline $\begin{array}{l}\text { Thinking } \\
\text { Narration } 1+3\end{array}$ & 3.13 & .97 & 3.00 & .77 & 3.59 & .49 & -.606 & - & -1.311 & - & -1.921 & - \\
\hline $\begin{array}{l}\text { Realizing } \\
\text { Narration } 2+4\end{array}$ & 3.06 & .87 & 3.12 & .72 & 3.65 & .45 & -.491 & - & -2.500 & $<.03$ & -3.464 & $<.006$ \\
\hline $\begin{array}{l}\text { Expressing } \\
\text { Actions } 1+2\end{array}$ & 3.12 & .86 & 2.95 & .87 & 3.72 & .46 & 1.141 & - & -2.489 & $<.03$ & -3.963 & $<.003$ \\
\hline $\begin{array}{l}\text { Expressing } \\
\text { Emotions } 3+4\end{array}$ & 3.04 & .96 & 3.22 & .64 & 3.63 & .45 & -.886 & - & -2.277 & $<.04$ & -1.845 & - \\
\hline $\begin{array}{l}\text { Right Words } \\
\text { and Gestures }\end{array}$ & 3.05 & .87 & 2.90 & .83 & 3.54 & .56 & 1.437 & - & -1.661 & - & -2.514 & $<.03$ \\
\hline
\end{tabular}

Regarding perceived confidence, the L2 group shows a greater initial security in the Thinking Narration category, while the L1 group seems to be more secure in Realizing Narration. This gap is also found in the sub-category Finding the Right Words and Gestures, in which Italian pupils perceive themselves as more competent.

Regarding the confidence about the most specific skills of communicating a narrative scene, L1 children feel more comfortable in Expressing Actions while the L2 group thinks they manage Expressing Emotions better. As has been demonstrated above, the improvements, although gradual and constant, do not make themselves evident in the early stages of the project. And initial comparisons between pre-test narration and post-test 1 theater are not as significant as those seen towards the end of the workshop, between post-test 1 theater and posttest- 2 video and between pre-test narration and posttest 2 video.

In particular, the L2 pupils' scores increase in Realizing Narration between pre-test narration and post-test 2 video $(\mathrm{t}(10)=-2.50, \mathrm{p}<.03$ ) and between post-test 1 theater and post-test 2 video ( $\mathrm{t}(10)=-3.46, \mathrm{p}<.006$ ). In Expressing Actions they improve between pre-test narration and post-test 2 video ( $\mathrm{t}(10)=-2.48, \mathrm{p}<.03$ ) and between post-test 1 theater and post-test 2 video ( $t(10)$ $=-3.96, \mathrm{p}<.003)$. In Expressing Emotions they improve between pre-test narration and post-test 2 video ( $\mathrm{t}(10)$ $=-2.27, \mathrm{p}$ <.04). In Finding Right Words and Gestures they improve between post-test 1 theater and post-test 2 video $(t(10)=-2.51, p<.03)$. The $L 1$ group shows significant increases in Expressing Emotions between pre-test narration and post-test 2 video $(\mathrm{t}(10)=-2.42, \mathrm{p}<.05$ ) and test 1 theatre and post-test 2 video $(\mathrm{t}(6)=-2.64$, $\mathrm{p}<.03)$.

\section{Discussion}

We can conclude from the results of this exploratory study that the multimodal-based workshop led, in gen- eral, to a significant increase in perceived self-efficacy for the whole class. Therefore, the first question (RQ1) has a positive answer. The children appreciated the activities, in particular the L2 group, which started disadvantaged in several categories in the pre-test narration. In Realizing Narration there was a difference of 0.08 points, and also for the category Right Words and Gestures there was a difference of 0.10 points, always to the disadvantage of the L2 group. This disadvantage did not only concern expression through words, but also through gestures, since the gap endured in the post-test phase 1 theater, in which the $L 2$ group perceived less confidence and greater effort than the L1 group, with almost 0.24 points difference. We are inclined to hypothesize that L2 students extended their insecurity in expressing themselves through words to their general expressive capacity, manifesting it in non-verbal activities, such as the gestural theater, in which the prevailing modality of expression is non-verbal.

Going into the details of the different steps, we note that the theatrical workshop produced the least significant improvements, compared to the subsequent digital video narration. However, the negative answer to the second research question (RQ2) can find different possible explanations. Primarily, we must consider the initial discrepancy in the self-efficacy level, previously mentioned. The $L 2$ group may have simply needed more time than the L1 group to gain self-confidence, due to their perceived effort and insecurity being greater from the start. We interpret the slow improvement of the $L 2$ group, such as it was, to the succession of different activities, which gradually reinforced their confidence.

We can respond positively to the third question (RQ3), on the role of video narration, as it significantly influenced the self-efficacy beliefs of narrative skills perceived by both L1 and L2 students. We believe that video workshops played a crucial role especially on three levels: (1) on a cognitive level, the video editing involved children in reworking the visual and writing narrative ele- 
ments. Indeed, we have observed that the children have committed themselves to writing and rewriting the texts on the computer several times, to change the images and texts on screen and to try various graphic solutions to make the product more effective, or as they said: "To make the narration more beautiful". They corrected each other when they wrote, for example: "Arrabbiato (Italian for angry) is spelled with two r's, not one". Moreover, it also had an effect (2) at the self-efficacy level: video editing allowed the children to review themselves in the photos and in the drawings and led them to appreciate their expressive performance; they said this made up for the low perception of self-efficacy that they had felt during the theatrical workshop. Indeed, during the video lab, the children, observing their photos and their drawings, commented to their classmates: "Uh, you see here how good Portia was at showing surprise for the riddle solution". Or about themselves: "Here, I should have stretched my arm out more to show the Bassanio ring"; "There, I was really dramatic. See how I keep my hands open and up!". Or simply: "I like this picture because I was acting really well". Finally, (3) the video allowed them to summarize their different activities in a single finished and tangible product, unlike the variable oral and theatrical narratives.

For these reasons, from an educational point of view, we believe that the digital video activity had the effect of building confidence and motivation in engaging in narration; above all, it reduced self-perceptions of insecurity. The combination of all these factors was helpful in determining the success of the workshop (in response to the RQ1 question).

More information is obtained by analyzing the answers to the fourth question (RQ4), which measured relative improvements in the various categories for each group. In particular, both groups displayed a remarkable recovery in the critical areas that were of major concern. The L2 group improved decisively in the categories Realizing Narrative, Expressing Actions and Right Words and Gestures to reach L1 group self-efficacy levels. Likewise, the L1 group, which had been less confident in Expressing Emotions, showed a notable improvement. In other aspects, too, an enhancement of confidence is almost consistently reported; these results, however, are probably not statistically significant since they start from higher scores compared to the critical areas.

\section{Research Limits}

Our study moved within the socio-cognitive theoretical framework of Bandura and specifically investigated the construct of self-efficacy of multimodal narrative activities in classes with a strong presence of foreign-origin students. This exploratory study aimed to discriminate some processes of multimodal narration in reception and production (see Section 3). In the future, we intend to broaden our field of investigation in order to generalize the educational potentialities and implications of multimodal narration, also on the level of social, cultural and digital inclusion. However, we think that this work can usefully inform those working in this field, both at the research level (researchers) and in the practical field (teachers).

A second limitation is related to the number of participants. Since only one class was involved, in which the number of Italian and foreign students, male and female, was not well balanced, the data cannot be considered in any way generalizable to a larger population. Replicating the study in other classes and in other contexts could enrich and help validate the available information.

The third limitation is intrinsic to the research design: a single group subjected to a pre-test and two post-tests. A control group would allow more accurate and sensible comparisons, although it should be emphasized that this type of educational activity requires a substantial effort in terms of time, resources and commitment by researchers and teachers involved.

The fourth limitation concerns the tools: although the questionnaire was internally validated, it was not possible to validate it externally as that would require a larger number of participants. We will elaborate further items, in particular the sources of Bandura's self-efficacy (Bandura, 1997). We intend to re-elaborate those items in the Feedback category that did not give statistically significant results. It will be necessary to verify if the problem resulted from an improper formulation or in difficulties of self-evaluation for 8-year-old children, whose metacognitive structures are still being developed.

Finally, it would have been interesting to compare these results with other research but unfortunately, for the reasons explained in Sections 1, 2 and 3, that was not possible.

\section{Educational Implications and Conclusions}

As our exploratory work shows, improvements in selfefficacy beliefs are not immediate. This implies that these processes have to be known and supported by teachers. In fact, we have recorded in the pre-text that the two groups (L1 and L2) were already starting with differences in perceptions of self-efficacy and when faced with new tasks (for example, the mime/gestural activity of the theatre) the difference tended to increase. The children had already learned processes of transferring self-efficacy from one activity to another and of generalizing self-efficacy based on their abilities (Bandura, 1997). Increasing the perception of self-efficacy takes a long time to achieve significant and lasting results. The development of rules and strategies for resilience is a sophisticated construct that begins to develop from primary age children, but requires opportunities and educational guidance for full achievement. Children of this age still appear uncertain about making accurate self-assessments (as we also found in our study), and they rely on the judgments of others to create their own beliefs of trust and self-esteem. The idea of the self in children of this age is 
like "mirror glass" (Pajares, 2002), as it is formed as a result of the perception of how others see or judge them, or from the feedback that children receive from adults.

Two implications arise naturally from these observations. The first is that teachers have a great responsibility to nurture the trust of their students, because personal beliefs can have positive or negative influences; the second is that they have a responsibility to develop educational activities that nurture and guide the students' sense of self-efficacy.

The current educational practices of teachers are predominantly verbal oriented and foreign students who leave with disadvantages in verbal expressive skills are at risk of repeated failures or slow improvements that provide little gratification. Multimodality, on the other hand, offers children the possibility of demonstrating their abilities with alternative modes of expression, of equal dignity to the verbal, and to find confirmation in their own abilities to face new challenges.

Multimodal narrative educational activities allow a broadening of the educational and pedagogical ambit: for example, even the repetition of the same topic in different ways has allowed children to master narrative patterns with different languages (gestural, visual, verbal and digital processing), which become part of their personal cultural heritage. Multimodality has allowed children to manipulate concepts, rules and narrative schemes, gradually transforming them from gestural thoughts/actions to verbal/visual and digital equivalents. This occurs both in reception and production (see Section 3), and avoids the monotony or excessive effort of the repetition of a single modality-the verbal one (see Sections 4 and 5).

In our experimental activities (theatrical, visual and digital), the children were exposed to continual verbalization, through which the teachers were enabled to encourage them, correct them and help them to improve their verbal skills. This extended to giving the children immediate feedback on their proposed activities.

For future research, we believe it is crucial to extend the survey to the self-efficacy of teachers who engage in multimodal educational practices in classes with a strong presence of foreigners, since the self-efficacy of teachers is a strong predictor of academic results of primary school children. It is important to study further how the self-efficacy of teachers influences that of their students, and further how the self-efficacy of the students influences one another. The aim is to obtain a more complete and better informed picture of the impact of multimodal practices in classes that contain a large presence of children of migrant origins.

\section{Acknowledgments}

This work is supported by EU project SHABEGH (CREATIVE EUROPE-CULTURE) (Project Reference: 570754CREA-1-2016-1-IT-CULT-COOP1). Note: for reasons of national assessment of Italian university research, the au- thors must declare which sections each has written, in spite of the fact that work is entirely the result of continuous and intensive collaboration. Sections 2, 4, 5, and 7 are by Monica Banzato. Sections 1, 3, and 6 are by Francesca Coin. Our thanks to Matthew Hoffman.

\section{Conflict of Interests}

The authors declare no conflict of interests.

\section{References}

Ballast, K., Stephens, L., \& Radcliffe, R. (2008). The effects of digital storytelling on sixth grade students' writing and their attitudes about writing. In K. McFerrin (Ed.), Proceedings of society for information technology and teacher education international conference 2008 (pp. 875-879). Chesapeake, VA: AACE.

Banaszewski, T. (2005). Digital storytelling, supporting digital literacy in grades 4-12 (Unpublished doctoral dissertation). Georgia Institute of Technology, Atlanta, GA. Retrieved from http://hdl.handle.net/ 1853/6966

Bandura, A. (1986). Social foundations of thought and action. Englewood Cliffs, NJ: Prentice Hall.

Bandura, A. (1997). Self efficacy: The exercise of control. New York, NY: W.H. Freeman and Co.

Binder, M., \& Kotsopoulos, S. (2011). Multimodal literacy narratives: Weaving the threads of young children's identity through the arts. Journal of Research in Childhood Education, 25(4), 339-363.

Caprara, G. V., Fida, R., Vecchione, M., Del Bove, G., Vecchio, G. M., Barbaranelli, C., \& Bandura, A. (2008). Longitudinal analysis of the role of perceived self-efficacy for self-regulated learning in academic continuance and achievement. Journal of Educational Psychology, 100(3), 525-534. https://doi.org/ 10.1037/0022-0663.100.3.525

Chen, G., Gully, S. M., \& Eden, D. (2001). Validation of a new general self-efficacy scale. Organizational Research Methods, 1(4), 62-83.

Dogan, B. (2015). Educational uses of digital storytelling in K-12: Research results of digital storytelling contest (DISTCO) 2014. In D. Rutledge \& D. Slykhuis (Ed.), Proceedings of SITE 2015-Society for Information technology \& teacher education international conference (pp. 595-604). Las Vegas, NV: AACE.

Gwénaëlle, J., \& Usher, E. B. P. (2011). Sources of selfefficacy: An investigation of elementary school students in France. Journal of Educational Psychology, 103(3), 649-663.

Heo, M. (2009). Digital storytelling: An empirical study of the impact of digital storytelling on pre-service teachers' self-efficacy and dispositions towards educational technology. Journal of Educational Multimedia and Hypermedia, 18(4), 405-428.

Honeyford, M. A. (2014). From aquí and allá: Symbolic convergence in the multimodal literacy practices of 
adolescent immigrant students. Journal of Literacy Research, 46(2), 194-233.

Ibanez, J., Aylett, R., Ruiz-Rodarte, R. (2003). Storytelling in virtual environments from a virtual guide perspective. Virtual Reality, 7(1), 30-42.

Jewitt, C. (2008). Multimodality and literacy in school classrooms. Review of Research in Education, 32(1), 241-267. https://doi.org/10.3102/ $0091732 \times 07310586$

Jewitt, C. (Ed.). (2009). The Routledge handbook of multimodal analysis. London: Routledge.

Klassen, R. M., \& Georgiou, G. K. (2008). Spelling and writing self-efficacy of Indo-Canadian and AngloCanadian early adolescents. Journal of International Migration and Integration/Revue de l'integration et de La Migration Internationale, 9(3), 311-326.

Klassen, R. (2002). Writing in early adolescence: A review of the role of self-efficacy beliefs. Educational Psychology Review, 2(14), 173-203.

Klassen, R. M. (2004). Optimism and realism: A review of self-efficacy from a cross-cultural perspective. International Journal of Psychology, 39(3), 205-230.

Kress, G. (2000). Multimodality. In M. Cope \& B. Kalantzis (Ed.), Multiliteracies: Literacy learning and the design of social futures. London: Routledge.

Massaro, D. W. (2012). Multimodal learning. In Encyclopedia of the Sciences of Learning (pp. 2375-2378). Boston, MA: Springer.

Ministero dell'Istruzione dell'Università e della Ricerca. (2016). Piano Nazionale Scuola Digitale [National Plan Digital School]. Rome: MIUR. Retrieved from http://www.istruzione.it/scuola_digitale/allegati/ Materiali/pnsd-layout-30.10-WEB.pdf

Ministero dell'Istruzione dell'Università e della Ricerca. (2017). Gli alunni stranieri nel sistema scolastico italiano a.s. 2015/2016 [Foreign students in the Italian school system 2015/2016]. Rome: MIUR. Retrieved from http://www.istruzione.it/allegati/ 2017/Notiziario_alunni_Stranieri_nelsistema_ scolastico_italiano_15_16.pdf

Nisbett, R., \& Ross, L. (1980). Human inference: Strategies and shortcomings of social judgment. Englewood Cliffs, NJ: Prentice-Hall.

NLG. (1996). A pedagogy of multiliteracies: Designing social futures. Harvard Educational Review, 66(1), 60-93. https://doi.org/10.17763/ haer.66.1.17370n67v22j160u

Ntelioglou, B. Y., Fannin, J., Montanera, M., \& Cummins, J. (2014). A multilingual and multimodal approach to literacy teaching and learning in urban education: A collaborative inquiry project in an inner city elementary school. Frontiers in Psychology, 5, 533.

OECD. (2009). Teaching practices, teachers' beliefs and attitudes. In Creating effective teaching and learning environments: First results from teaching and learn- ing international survey (pp. 87-135). Paris: OECD Publishing. Retrieved from https://www.oecd.org/ education/school/43023606.pdf

OECD-PISA. (2012). Risultati PISA 2012. Nota paese Italia [PISA 2012 results. Country note Italy]. Paris: OECD Publishing. Retrieved from https://www.oecd.org/ pisa/keyfindings/PISA-2012-results-italy-ITA.pdf

Pajares, F. (2002). Gender and perceived self-efficacy in self-regulated learning. Theory Into Practice, 41(2), 116-125.

Pajares, F. (2003). Self-efficacy beliefs, motivation, and achievement in writing: A review of literature. Reading \& Writing Quarterly, 2(19), 139-158.

Redecker, C. (2017). European framework for the digital competence of educators. Brussels: European Commision.

Santagati, M., \& Ongini, V. (2016). Alunni con cittadinanza non italiana. La scuola multiculturale nei contesti locali. Rapporto nazionale A.S. 2014/2015 [Pupils with non-Italian citizenship. Multicultural school in local contexts. National report 2014/2015] (Vol. 1/2016). Milano: Fondazione ISMU.

Scaffidi, C., \& Chambers, C. (2012). Skill progression demonstrated by users in the Scratch animation environment. International Journal of Human-Computer Interaction, 28(6), 383-398.

Shin, B. J., \& Park, H. S. (2008). The effect of digital storytelling type on the learner's fun and comprehension in virtual reality. Journal of the Korean Association of Information Education, 12(4), 417-425.

Stoll-Lillard, A. (2005). Montessori: The science behind the genius. Oxford: Oxford University Press.

Tosi, L. (2015). II Mercante di Venezia da William Shakespeare [The merchant of Venice by William Shakespeare]. Roma: Lapis edizioni.

Usher, E. L., \& Pajares, F. (2008). Sources of selfefficacy in school: Critical review of the literature and future directions. Review of Educational Research, 78(4), 751-796. https://doi.org/10.3102/ 0034654308321456

Walsh, M. (2010). Multimodal literacy: What does it mean for classroom practice? Australian Journal of Language and Literacy, 33(3), 211-239.

Wilber, D. J. (2010). Special themed issue: Beyond 'new' literacies. Digital Culture \& Education, 2(1), 1-6. Retrieved from http://www. digitalcultureandeducation.com/cms/wp-content/ uploads/2010/05/dce_editorial_wilber_2010.pdf

Yoon, T. (2013). Are you digitized? Ways to provide motivation for ELL's using digital storytelling. International Journal of Research Studies in Educational Technology, 2(1), 25-34.

Zimmerman, B. J. (2002). Becoming a self-regulated learner: An overview. Theory into Practice, 2(41), 64-70. 


\section{COGITATIO}

\section{About the Authors}

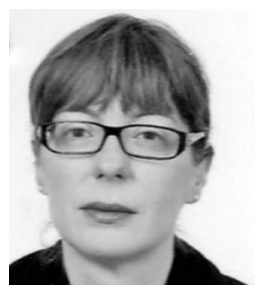

Monica Banzato (PhD in Educational Sciences) is a Lecturer and Researcher in Educational Research and Developmental Cognitive Psychology at Ca' Foscari University of Venice. Since 1996, she has been active in the field of educational and training technology-theory and applications. She has participated as a researcher in several EU research projects, including: digital competencies for teachers' educational development; open educational resources/practice; self-efficacy and gender difference in handmade robotics; and digital/media narration for K12.

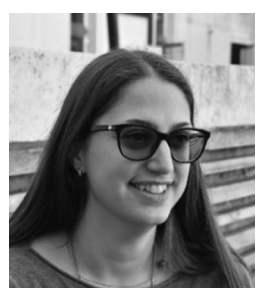

Francesca Coin is Developmental Psychologist (PhD in Science of Cognition and Education). She collaborates with Ca' Foscari University and the CTS of Venice (Territorial Support Centre for New Technologies in Inclusive Education) where she teaches Developmental Cognitive Psychology in the specialized training for teachers. She is interested in inclusive teaching for foreign students and students with disabilities. She is involved in several digital education research projects for K12, such as the European project SHABEG. 


\section{Appendix}

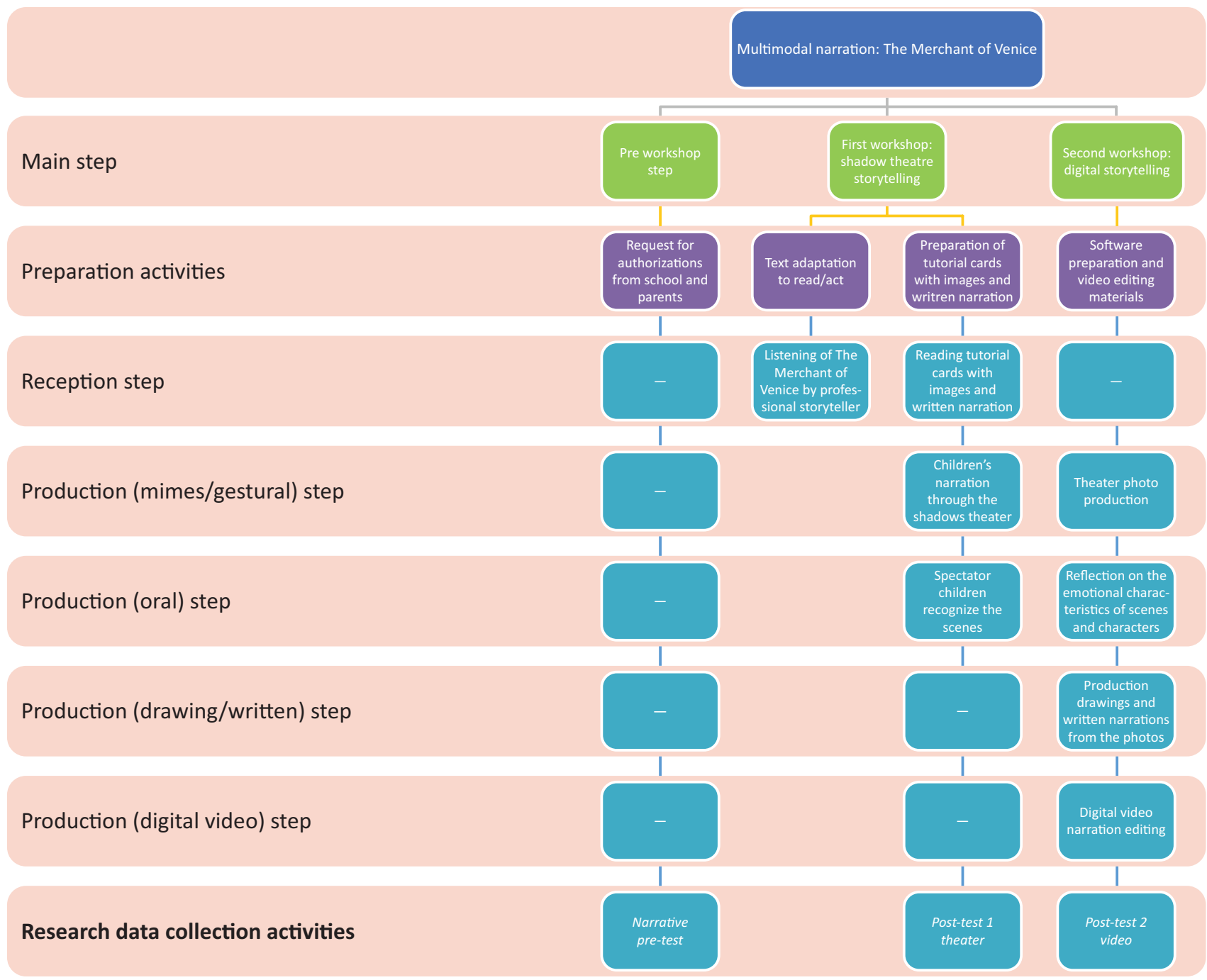

Figure 1. The phases of the exploratory study and the educational narrative workshops. 